\title{
Evaluation of High-Temperature Exposure of Photovoltaic Modules
}

Conference Paper NREL/CP-520-45986 June 2009

\section{Preprint}

S. Kurtz, D. Miller, M. Kempe, and N. Bosco National Renewable Energy Laboratory

K. Whitefield Miasole

J. Wohlgemuth

BP Solar

N. Dhere

Florida Solar Energy Center

T. Zgonena

Underwriters Laboratories Inc.

To be presented at the $34^{\text {th }}$ IEEE Photovoltaic Specialists Conference Philadelphia, Pennsylvania June 7-12, 2009 


\section{NOTICE}

The submitted manuscript has been offered by an employee of the Alliance for Sustainable Energy, LLC (ASE), a contractor of the US Government under Contract No. DE-AC36-08-GO28308. Accordingly, the US Government and ASE retain a nonexclusive royalty-free license to publish or reproduce the published form of this contribution, or allow others to do so, for US Government purposes.

This report was prepared as an account of work sponsored by an agency of the United States government. Neither the United States government nor any agency thereof, nor any of their employees, makes any warranty, express or implied, or assumes any legal liability or responsibility for the accuracy, completeness, or usefulness of any information, apparatus, product, or process disclosed, or represents that its use would not infringe privately owned rights. Reference herein to any specific commercial product, process, or service by trade name, trademark, manufacturer, or otherwise does not necessarily constitute or imply its endorsement, recommendation, or favoring by the United States government or any agency thereof. The views and opinions of authors expressed herein do not necessarily state or reflect those of the United States government or any agency thereof.

Available electronically at http://www.osti.gov/bridge

Available for a processing fee to U.S. Department of Energy and its contractors, in paper, from:

U.S. Department of Energy

Office of Scientific and Technical Information

P.O. Box 62

Oak Ridge, TN 37831-0062

phone: 865.576 .8401

fax: 865.576 .5728

email: mailto:reports@adonis.osti.gov

Available for sale to the public, in paper, from:

U.S. Department of Commerce

National Technical Information Service

5285 Port Royal Road

Springfield, VA 22161

phone: 800.553.6847

fax: 703.605.6900

email: orders@ntis.fedworld.gov

online ordering: http://www.ntis.gov/ordering.htm 


\title{
EVALUATION OF HIGH-TEMPERATURE EXPOSURE OF RACK-MOUNTED PHOTOVOLTAIC MODULES
}

\author{
Sarah Kurtz, ${ }^{1}$ Kent Whitfield, ${ }^{2}$ David Miller, ${ }^{1}$ James Joyce,${ }^{5}$ John Wohlgemuth, ${ }^{3}$ Michael Kempe, ${ }^{1}$ Neelkanth Dhere,${ }^{4}$ Nick \\ Bosco, ${ }^{1}$ and Timothy Zgonena ${ }^{5}$ \\ ${ }^{1}$ National Renewable Energy Laboratory, Golden, CO 80401 \\ ${ }^{2}$ Miasolé, Santa Clara, CA, 95051 - \\ ${ }^{3}$ BP Solar, Frederick, MD, 21703 - \\ ${ }^{4}$ Florida Solar Energy Center, Cocoa, FL, 32922 - \\ ${ }^{5}$ Underwriters Laboratories Inc., Northbrook, IL, 60062 -
}

\begin{abstract}
Photovoltaic (PV) modules operate in an extreme environment and are exposed to radiation, humidity, and hot and cold thermal extremes. This paper focuses on polymeric-material degradation during PV-module operation at high ambient temperatures, high solar irradiance and low wind speed. The 2004 version of the IEC 61730 specification requires all polymeric materials used in a photovoltaic module to have a Relative Thermal Index (RTI) or Relative Thermal Endurance Index (RTE) at least $20^{\circ} \mathrm{C}$ greater than the maximum material temperature measured during the temperature test conducted at $40^{\circ} \mathrm{C}$ ambient. There is currently an international debate regarding this requirement. This paper explores the thermal exposure of photovoltaic modules in the field as a technical basis for this debate. For the hottest cities, the thermal exposure is found to be equivalent to aging at a constant temperature of $42-53^{\circ} \mathrm{C}$, with maximum temperatures of $75^{\circ} \mathrm{C}$.
\end{abstract}

\section{INTRODUCTION}

Establishing the long-term safety of photovoltaic (PV) modules depends on screening the modules with appropriate accelerated-aging tests. Past studies elucidate how $\mathrm{PV}$ modules may be tested to more quickly identify failure modes [1-5]. McMahon documented how to calculate the acceleration factor for accelerated thermal testing if the temperature dependence of the aging is quantified [6]. Procedures for determining the RTI or RTE quantify degradation of critical material properties at multiple temperatures, providing a basis to extrapolate the material's thermal capability to timeframes beyond the experiment timeframe.

This study documents only the thermal environment and the test requirements associated with high temperatures. The effects of humidity and ultraviolet (UV) light, although critically important, are not treated here to allow a more detailed examination of the thermal environment. This study investigates thermal exposure including: (1) long-term, cumulative exposure, and (2) short-term, hightemperature exposure. Long-term material degradation and the short-term effects of a phase change of a material elicit different physical processes that must be examined separately. This paper documents measured and modeled PV-module temperatures and evaluates these in the context of the requirements for accelerated testing.

\section{THERMALLY ACTIVATED LONG-TERM AGING}

Material aging accumulates from numerous stresses including UV exposure, moisture, and mechanical loads. Most aging processes are accelerated with temperature. The thermal history experienced by a PV module can degrade some polymeric components even without addition of UV, moisture, or other stress. This analysis focuses on the role of temperature in aging, but also acknowledges the importance of other stresses.

If a single mechanism determines aging within the temperature range of interest, then the rate of aging of a material can be approximated by the Arrhenius equation:

$$
\text { Rate } \propto \exp \left[\frac{-E_{a}}{k T}\right] \text {, }
$$

where $E_{a}$ is the effective activation energy of the aging process, $k$ is Boltzmann's constant, and $T$ is the sample temperature.

The temperature dependence of the rate of a chemical reaction, as calculated from Eq. 1, is very dependent on the activation energy, $E_{a}$. Relative reaction rates are plotted as a function of inverse temperature in Fig. 1 for three values of $E_{a}$. In general, reaction rates are dependent on multiple mechanisms and may follow Eq. 1 over only a narrow temperature range, because different degradation mechanisms become important at higher temperatures [7]. Nevertheless, chemists usually use Eq. 1 to model the thermal dependence of reaction rates.

As shown in Fig. 1, for two processes with the same reaction rate at $50^{\circ} \mathrm{C}$, the rate at $100^{\circ} \mathrm{C}$ will be about 1000 times faster for a process with $E_{a}=2 \mathrm{eV}$ relative to a process with $E_{a}=0.6 \mathrm{eV}$. For all three cases, increasing temperature accelerates the reaction rate, but accurate prediction of the acceleration factor requires accurate knowledge of $E_{a}$. In general, the linear behavior shown in 
Fig. 1 is observed only when a single reaction mechanism is dominant and when no phase transitions occur in the same temperature range.

The $\mathrm{RTI}^{1}$ is based on application of eq. 1. Four timetemperature data points are typically used to establish a linear relationship of good correlation, thus providing a basis to extrapolate the material's thermal capability to timeframes beyond the experiment timeframe, something a single-temperature accelerated test cannot do. The samples are examined periodically to detect a $50 \%$ change in the characteristic of interest. [8]

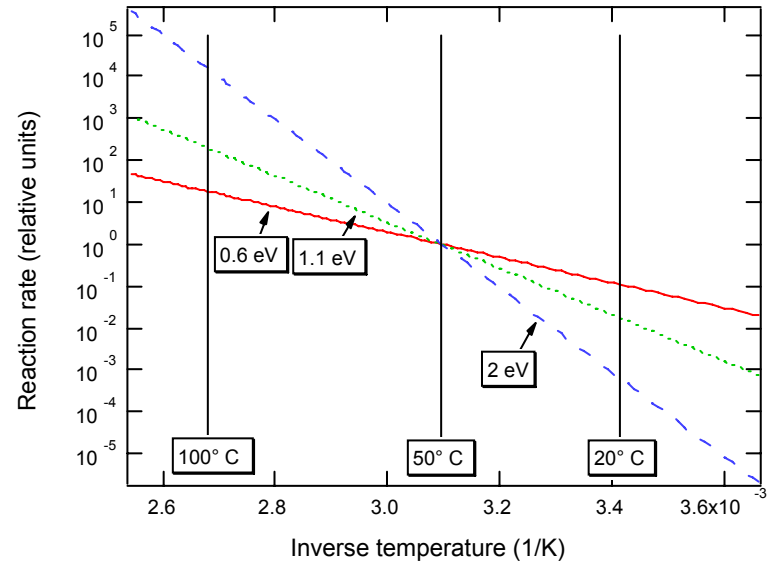

Fig. 1. Relative reaction rates for chemical processes with $E_{a}=0.6,1.1$, or $2 \mathrm{eV}$ plotted versus the inverse of the reaction temperature.

The dependence on temperature, i.e., $E_{a}$, is effectively determined as part of the RTI/RTE determination for each characteristic of each material. In general, $E_{a}$ is not known a priori, but may be estimated from known values for similar materials. A review of aged polymeric materials [9] found that the most frequently observed $E_{a}$ was about $1.1 \mathrm{eV}$. For this study, we vary $E_{a}$ between 0.6 and $2 \mathrm{eV}$, consistent with the range of $E_{a}$ values reported in Ref. [9] for 170 measured values of $E_{a}$.

\section{Definition of equivalent temperature}

The operating temperature for a module varies throughout its life. If aging of a module follows Eq. 1, it is possible to define an equivalent temperature, $T_{\text {eq }}$, to represent the aging that would have taken place if the module had been aged for the same time, but at a con-

1 UL 746B defines "relative thermal index" as "an indication of the material's ability to retain a particular property (physical, electrical, etc.) when exposed to elevated temperatures for an extended period of time. It is a measure of the material's thermal endurance. For each material, a number of relative thermal indices can be established, each index related to a specific property and a specific thickness of the material." stant (equivalent) temperature. $T_{\text {eq }}$ can be calculated from the thermal history of the module using Eq. 2:

$$
\exp \left(-E_{a} / k T_{e q}\right)=\frac{1}{t_{1}-t_{2}} \int_{t_{1}}^{t_{2}} \exp \left(-E_{a} / k T(t)\right) d t \text {, }
$$

where $t$ is time and the limits of integration are times $t_{1}$ and $t_{2}$. This approach to defining an equivalent temperature is described elsewhere [6,10]. For a given moduletemperature history, the equivalent temperature can be calculated from Eq. 2 using numerical integration. From the compilation [9] of common values for $E_{a}$, analysis was performed for three values of $E_{a}$.

The data history used to calculate $T_{e q}$ may be modeled using weather data (ambient temperature, irradiance, and wind speed) from a hot location, or may be taken from actual module data. Here, we present calculations based on both modeled and actual data.

\section{Equivalent temperature for multiple locations}

For this study, we used two module-temperature data sets: one measured in Florida and one measured in Colorado. Both sets of modules were deployed in openrack configurations with latitude tilt and 15-min-averagetemperature monitoring on the backs of the modules. The Florida modules were deployed at the Florida Solar Energy Center. These were Shell Solar modules with a glass-CIGS-glass construction. The Colorado modules were deployed at NREL and were (glass-silicon-backsheet) ASE GP300DG Si ribbon modules. $T_{e q}$ values for the Florida dataset are summarized for each month of one year in Table 1 and Fig. 2.

Module-temperature data were not identified for all critical locations. To extend the study to some very hot locations, we used Typical Meteorological Year (TMY), specifically TMY3, data [11] to estimate the module temperature from the irradiance and the wind speed using Eq. 3 [12],

$T_{m}=T_{a m b}+$ Irradiance $\times \exp [-3.473-0.0594 \times W S]$,

where $T_{m}$ is the module temperature $\left({ }^{\circ} \mathrm{C}\right)$, Irradiance is the plane-of-array (POA) irradiance $\left(\mathrm{W} / \mathrm{m}^{2}\right), T_{a m b}$ is the ambient temperature $\left({ }^{\circ} \mathrm{C}\right)$, and $W S$ is the wind speed $(\mathrm{m} / \mathrm{s})$. The weather data were either measured or taken from the TMY3 database. When taken from the TMY3 database, the POA irradiance was calculated [13] from

$$
\text { Irradiance }=G H I \times \frac{\cos [A O I]}{\cos [\text { zenith }]},
$$

where $\mathrm{GHI}$ is the global horizontal irradiance $\left(\mathrm{W} / \mathrm{m}^{2}\right)$ data in the TMY3 database, the AOI angle is the angle between the sun and the latitude-tilt POA, and the zenith angle is the angle between the sun and the zenith. Equation 4 is exact for the direct beam; conversion of the diffuse part of $\mathrm{GHI}$ to the diffuse irradiance on the POA requires knowl- 
edge of the ground albedo. The more exact calculation changes $T_{\text {eq }}$ by $<-1^{\circ}$ or $+1^{\circ} \mathrm{C}$ for albedo of 0 or 1 , respectively. Equation 3 is designed to predict the module temperature for a rack-mounted, glass-glass module; it predicts the monthly average of the module temperature within $2^{\circ} \mathrm{C}$ for the data in Table 1 and Fig. 2. Equation 3 tends to slightly overestimate the module temperature, especially on clear nights when the modules radiate energy into space, causing them to cool $1^{\circ}-2^{\circ} \mathrm{C}$ below ambi- ent temperature. A comparison of about 10 days of measured and modeled module-temperature data is shown in Fig. 3. The measured data shown in Fig. 3 are a subset of the dataset from Florida. The modeled moduletemperature data are carefully compared with the actual measured module-temperature data in Figs. 2 and 3 and Table 1-to gain confidence in Eq. 3 and to be able to apply the methodology to any location for which we have weather data, but no module-temperature data.

Table 1. Summary of thermal history over one year for a module deployed in Florida in an open-rack-mounted configuration. The modeled module-temperature data were derived from the measured weather data using Eq. 3 . $T_{\text {eq }}$ was calculated from Eq. 2 using the indicated values of $E_{a}$. All temperatures are ${ }^{\circ} \mathrm{C}$.

\begin{tabular}{|l|c|c|c|c|c|c|c|c|c|}
\hline \multirow{2}{*}{ Month } & \multicolumn{2}{|c|}{ Ambient T } & \multicolumn{2}{|c|}{ Measured Module T } & \multicolumn{2}{c|}{ Modeled Module T } & \multicolumn{3}{c|}{ Equivalent T } \\
\cline { 2 - 10 } & Ave. & Max. & Ave. & Max. & Ave. & Max. & $E_{a}=0.6 \mathrm{eV}$ & $E_{a}=1.1 \mathrm{eV}$ & $E_{a}=2 \mathrm{eV}$ \\
\hline Jan & 18.0 & 33.6 & 21.1 & 58.3 & 23.1 & 63.8 & 26.1 & 30.8 & 37.0 \\
\hline Feb & 15.8 & 27.2 & 19.7 & 58.1 & 21.6 & 57.8 & 26.4 & 32.0 & 38.2 \\
\hline Mar & 19.6 & 30.7 & 25.0 & 62.0 & 26.3 & 59.4 & 32.0 & 37.5 & 43.4 \\
\hline Apr & 21.0 & 31.4 & 26.8 & 61.6 & 27.9 & 60.1 & 33.8 & 39.2 & 44.7 \\
\hline May & 23.8 & 30.2 & 29.5 & 60.0 & 30.2 & 58.7 & 34.8 & 39.5 & 44.9 \\
\hline Jun & 26.0 & 34.4 & 31.8 & 70.6 & 31.9 & 63.7 & 37.3 & 42.3 & 48.5 \\
\hline Jul & 26.6 & 34.4 & 32.3 & 69.1 & 31.8 & 62.3 & 38.7 & 44.3 & 50.5 \\
\hline Aug & 28.4 & 40.7 & 33.5 & 66.5 & 35.1 & 69.9 & 39.8 & 44.9 & 50.3 \\
\hline Sep & 26.2 & 34.1 & 32.2 & 69.7 & 32.9 & 65.7 & 38.6 & 44.0 & 49.9 \\
\hline Oct & 23.0 & 33.2 & 28.4 & 67.1 & 29.6 & 63.3 & 35.0 & 40.3 & 46.2 \\
\hline Nov & 18.5 & 29.3 & 22.7 & 61.3 & 24.2 & 56.3 & 28.6 & 33.6 & 39.6 \\
\hline Dec & 20.1 & 28.4 & 23.2 & 56.4 & 24.3 & 54.3 & 27.2 & 31.4 & 37.3 \\
\hline Year & $\mathbf{2 2 . 3}$ & $\mathbf{4 0 . 7}$ & $\mathbf{2 7 . 2}$ & $\mathbf{7 0 . 6}$ & $\mathbf{2 8 . 2}$ & $\mathbf{6 9 . 9}$ & $\mathbf{3 3 . 3}$ & $\mathbf{3 9 . 5}$ & $\mathbf{4 6 . 4}$ \\
\hline
\end{tabular}

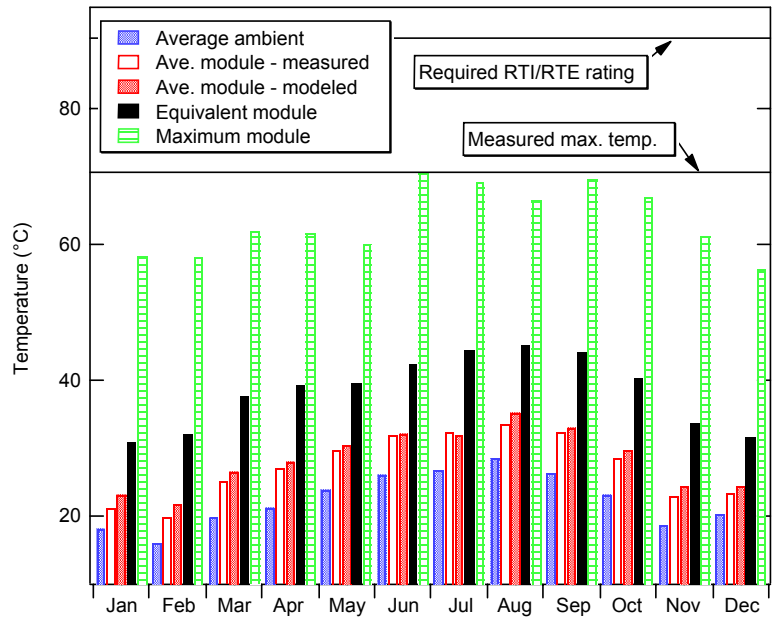

Fig. 2. Thermal history from Table 1, including $T_{\text {eq }}$ calculated for $E_{a}=1.1 \mathrm{eV}$. The lines across the top estimate the expected maximum operating temperature and the associated required $\mathrm{RTI} / \mathrm{RTE}$ rating.

In Fig.4, $T_{\text {eq }}$ values calculated for the measured data in Florida and Colorado and modeled from the average weather data [11] for Luxor (Egypt), Riyahd (Saudi Arabia), and Kuwait International Airport (Kuwait) are plotted as a function of $T_{a m b}$. The open symbols show monthly averages; the solid symbols indicate the annual average. The relationship between average ambient temperature and the equivalent module temperature appears

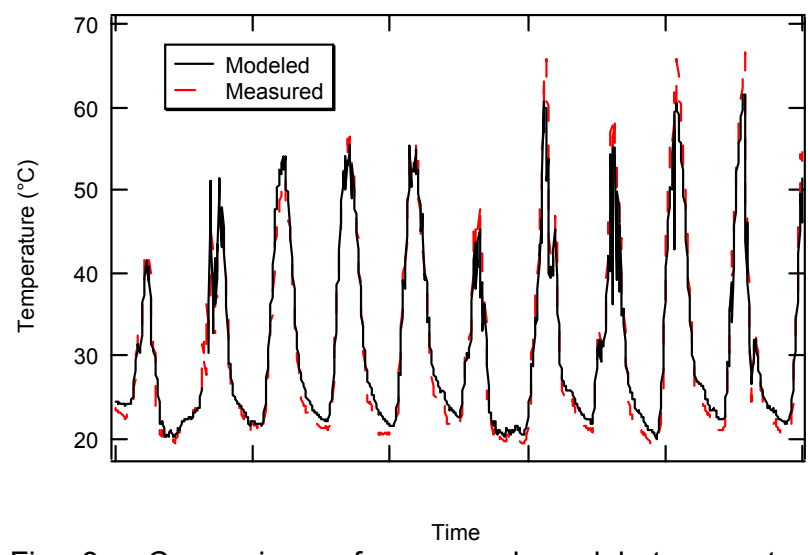

Fig. 3. Comparison of measured module-temperature data with analytical data (Eq. 3) for 10 days in Florida.

to be relatively independent of location, i.e., site-specific climate.

\section{Hottest locations}

As shown in Fig. 4, the calculated $T_{\text {eq }}$ shows a clear correlation with the average ambient temperature. Although the local sunshine, wind speed, and other variables affect the equivalent temperature, these effects are relatively small. Data for average ambient temperatures are readily available for many locations around the world. In Table 2, Bangkok, Thailand, has the highest average 


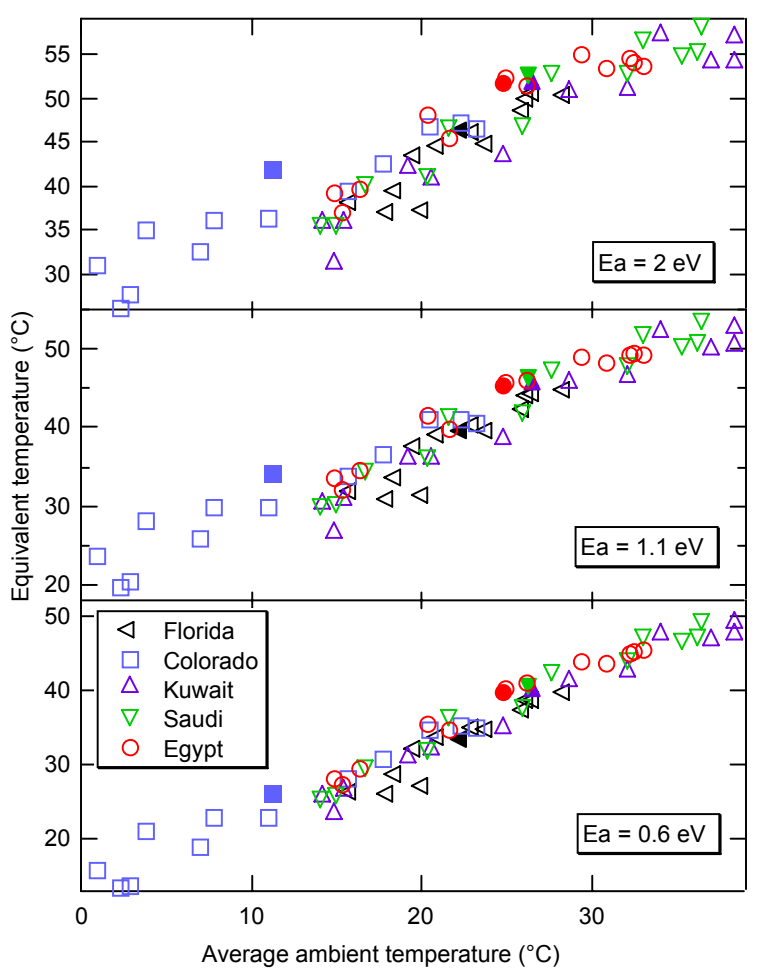

Fig. 4. $T_{e q}$ vs. monthly average ambient temperature. The solid symbols represent the average for the entire year. The data for Florida (Table 1) and Colorado were collected for rack-mounted systems; the data from the Middle East were modeled from weather conditions using Eq. 3.

ambient temperature of $28.1^{\circ} \mathrm{C}$. Other reports indicate that $29^{\circ} \mathrm{C}$ may be the highest documented average temperature for any city [14].

$T_{\text {eq }}$ values from Fig. 4 are summarized in Table 3. Additional uncertainty is associated with the mounting configuration and the difference between measured temperature of the module and the temperature of its component materials. Roof-mounted modules are expected to operate at higher temperatures. $T_{\text {eq }}$ for roof-mounted systems shows stronger dependence on total solar irradiance. Similarly, tracked systems experience higher average module temperatures. This will be treated in more detail elsewhere.

Table 3 shows that $T_{\text {eq }}$ for the hottest locations in the world vary between $42^{\circ}$ and $53^{\circ} \mathrm{C}$, depending on the $E_{a}$ used in the analysis. For more moderate climates, values of $T_{e q}$ range between about $30^{\circ}$ and $40^{\circ} \mathrm{C}$. The temperatures in Table 3 are substantially lower than the maximum temperatures for the modules on the hottest days. Because some polymers may age in this temperature range, it may be useful to accelerate this degradation by the application of a higher temperature.

Currently, modules are stressed at $85^{\circ} \mathrm{C}$ and $85 \%$ relative humidity for 1000 hours as part of the IEC 61215 and IEC 61646 qualification tests [16]. The methodologies
Table 2. Summary of annual average ambient temperature for some familiar locations [15]

\begin{tabular}{|l|c|}
\hline Location & Average temperature $\left.\mathbf{~}^{\circ} \mathbf{C}\right)$ \\
\hline Bangkok, Thailand & 28.1 \\
\hline Jakarta, Indonesia & 26.8 \\
\hline Lagos, Nigeria & 26.5 \\
\hline Karachi, Pakistan & 26.0 \\
\hline New Delhi, India & 25.0 \\
\hline Kinshasa, Zaire & 24.5 \\
\hline Miami, FL, USA & 24.0 \\
\hline Hong Kong & 23.1 \\
\hline Baghdad, Iraq & 22.7 \\
\hline Phoenix, AZ, USA & 22.6 \\
\hline Tucson, AZ, USA & 21.1 \\
\hline Cairo, Egypt & 21.0 \\
\hline Tripoli, Libya & 20.4 \\
\hline Tel Aviv, Israel & 19.4 \\
\hline Sao Paulo, Brazil & 18.3 \\
\hline Lima, Peru & 18.2 \\
\hline San Diego, CA, USA & 17.8 \\
\hline Sydney, Australia & 17.5 \\
\hline Tehran, Iran & 16.7 \\
\hline Mexico City, Mexico & 15.9 \\
\hline Lisbon, Portugal & 15.9 \\
\hline Shanghai, China & 15.4 \\
\hline Rome, Italy & 15.4 \\
\hline Tokyo, Japan & 14.5 \\
\hline Madrid, Spain & 14.2 \\
\hline Istanbul, Turkey & 14.1 \\
\hline San Francisco, CA, USA & 13.9 \\
\hline Bogota, Colombia & 13.1 \\
\hline Beijing, China & 11.8 \\
\hline London, UK & 11.7 \\
\hline Paris, France & 11.0 \\
\hline Berlin, Germany & 8.9 \\
\hline & \\
\hline
\end{tabular}

Table 3. Summary of average ambient temperatures and $T_{\text {eq }}$ values from Fig. 4 using $E_{a}=0.6,1.1$, and $2 \mathrm{eV}$ for rack-mounted $\mathrm{PV}$ modules. All temperatures are ${ }^{\circ} \mathrm{C}$.

\begin{tabular}{|l|c|c|c|c|}
\hline Location & $\begin{array}{c}\text { Average } \\
\text { ambient }\end{array}$ & \multicolumn{3}{|c|}{$\begin{array}{c}\text { Equivalent module tem- } \\
\text { perature }\end{array}$} \\
\cline { 3 - 5 } & & $\mathbf{0 . 6} \mathbf{~ e V}$ & $\mathbf{1 . 1} \mathbf{~ e V}$ & $\mathbf{2 ~ e V}$ \\
\hline Hot location & 29 & 42 & 47 & 53 \\
\hline Kuwait & 26.5 & 38.9 & 45.2 & 52.1 \\
\hline Saudi Arabia & 26.2 & 40.2 & 46.2 & 52.9 \\
\hline Egypt & 24.8 & 39.3 & 45.3 & 52.2 \\
\hline Florida & 22.3 & 33.3 & 39.5 & 46.4 \\
\hline Colorado & 11.2 & 26.1 & 34.1 & 41.9 \\
\hline
\end{tabular}

for determining RTI and RTE have subtle differences that are difficult to define because of flexibility in how the standards are applied. Both IEC 60216-5 and UL746B use simultaneous aging with a reference material to identify the aging, or correlation, time, which is usually between 20,000 $\mathrm{h}$ and 100,000 h. [8] Although these times are shorter than desired for PV module lifetime, UL uses this approach, based on years of observations that materials that retain their properties for 100,000 hours in the field can be regarded as stable for most applications. Table 4 compares the time and temperature that would be 
needed to simulate $20,000-100,000$ hours in the field for the $T_{a m b}$ of $29^{\circ} \mathrm{C}$, the hottest average temperature documented for any city in the world.

Table 4. Extrapolated $T_{\text {eq }}$ for a location with an average $T_{\text {amb }}$ of $29^{\circ} \mathrm{C}$ (see Table 3 ) and the corresponding test conditions that would be needed to simulate 20,000 or 100,000 hours at that temperature.

\begin{tabular}{|c|c|c|c|c|c|}
\hline $\begin{array}{c}E_{a} \\
(\mathrm{eV})\end{array}$ & \begin{tabular}{c}
$T_{\text {eq }}\left({ }^{\circ} \mathrm{C}\right)$ \\
\multicolumn{2}{|c|}{}
\end{tabular} & \multicolumn{2}{|c|}{$\begin{array}{c}\text { Time at } 85^{\circ} \mathrm{C} \\
(\mathrm{h})\end{array}$} & \multicolumn{2}{c|}{$\begin{array}{c}\text { Temperature for } \\
1000 \text { hour test } \\
\left({ }^{\circ} \mathrm{C}\right)\end{array}$} \\
\hline \multicolumn{2}{|c|}{ Correlation time (h) } & 20,000 & 100,000 & 20,000 & 100,000 \\
\hline 0.6 & $42 \pm 5$ & 1410 & 7040 & $91 \pm 7$ & $125 \pm 8$ \\
\hline 1.1 & $47 \pm 5$ & 290 & 1450 & $73 \pm 6$ & $89 \pm 7$ \\
\hline 2.0 & $53 \pm 5$ & 35 & 173 & $67 \pm 6$ & $76 \pm 6$ \\
\hline
\end{tabular}

\section{Discussion of long-term thermal aging}

Table 4 suggests that, for aging mechanisms with large $E_{a}$, a test condition of 1000 hours at $85^{\circ} \mathrm{C}$ (as is used in the damp-heat test) applies similar stress to that applied during the RTI/RTE testing. For aging mechanisms with small $E_{a}$, the damp-heat test does not apply as much stress as the RTI/RTE testing.

Many aging mechanisms are accelerated in the presence of moisture, which has not yet been considered. A prior study suggested that an increase of $1 \%$ in relative humidity accelerates aging about the same as $1^{\circ} \mathrm{C}$ rise in temperature for degradation associated with corrosion [17], but it is not likely that this correlation would hold for aging of all polymeric materials. For cooler locations the numbers in Table 4 would be decreased. Thus, the dampheat test appears to be more stringent than the RTI/RTE test when $E_{a}=2.0 \mathrm{eV}$ and less so when $E_{a}=0.6 \mathrm{eV}$. A quantitative comparison of the different test methods depends on $E_{a}$, the correlation time, and the failure criteria (the RTI depends on $50 \%$ degradation; whereas the IEC damp-heat test checks module performance). If RTI/RTE testing predicts adequate stability, then for $E_{a}=2 \mathrm{eV}$, the damp-heat test should also predict adequate stability, but when $E_{a}$ is small, there is added risk if damp-heat is used alone.

\section{SHORT-TERM, HIGH-TEMPERATURE EXPOSURE}

If a PV module experiences a temperature that causes a dramatic phase transition of a component material, the module may degrade very rapidly. The physical process driving such changes is very different from the thermally activated aging described by Eq. 1, as discussed above. Thermally activated degradation is a cumulative process that depends on the entire thermal history, whereas changes caused by exposure to temperatures near a phase-transition temperature may occur very quickly and may be dependent on a single high-temperature event. Thus, the evaluation of the possibility of a phase transition focuses on the high end of the temperature distribution curve. The very highest temperatures are expected on the hottest days of the year, when the sun is brightest. One set of temperature data is shown in Fig. 5 for the same Florida dataset described above in Table 1.

\section{Hottest module temperatures for multiple locations}

The Florida dataset is shown along with similar data for other locations in Fig. 6. The multiple datasets are the same as those used for calculating the data in Fig. 4. The module-temperature data are expected to be strongly dependent on module mounting configuration. To better explore this, the module temperatures were modeled with a modified version of Eq. 3, using coefficients that are known to approximate the temperatures observed for direct roof mounting [12]:

$T_{m}=T_{a m b}+$ Irradiance $\times \exp [-2.98-0.0471 \times W S]$.

The distribution of module temperatures for the roofmounted configuration is shown in Fig. 7. The module temperatures calculated for $40^{\circ} \mathrm{C}$ ambient and $1000 \mathrm{~W} / \mathrm{m}^{2}$ from Eq. 3 for open-rack mount and Eq. 6 for direct roof mount are $70.0^{\circ} \mathrm{C}$ and $90.8^{\circ} \mathrm{C}$, respectively. These are similar to temperatures typically measured for modules using the IEC 61730 temperature test.

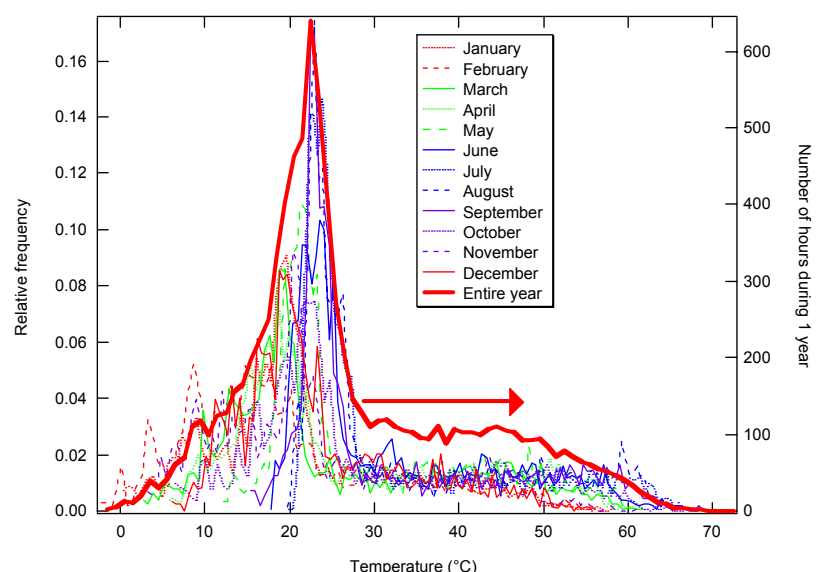

Fig. 5. Distribution of module temperatures measured for a module rack-mounted in Florida for each month of one year (left axis) and the sum of these (thick line, right axis).

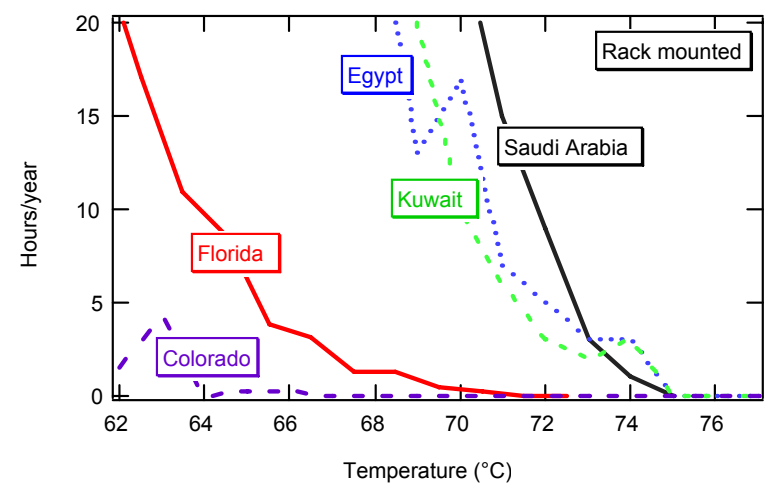

Fig. 6. Distribution of rack-mounted module temperatures for five sites (Florida data are the same as in Fig. 5.) Modeled data are used for the three Middle East sites. 


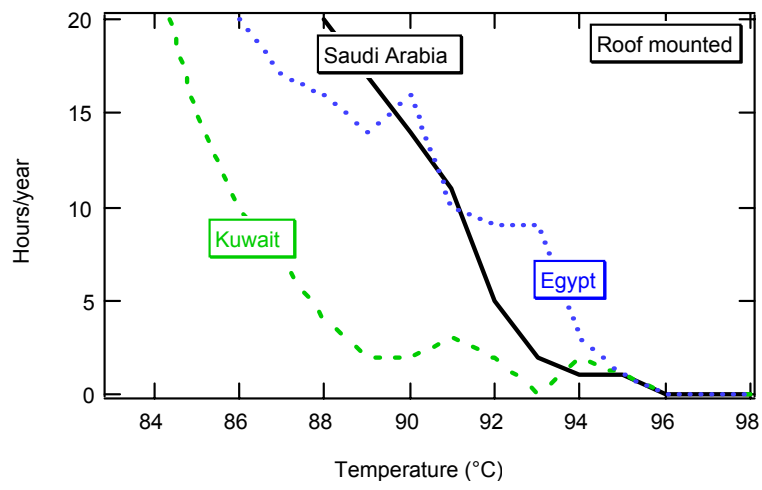

Fig. 7. Distribution of module temperatures modeled for a roof-mounted configuration for three Middle East locations.

\section{CONCLUSIONS}

Regarding long-term thermal aging, we conclude that rack-mounted modules in the hottest parts of the world age as though they are constantly maintained at a temperature of about $42^{\circ}-53^{\circ} \mathrm{C}$. Other conclusions include:

1. - Based on data in Table 4, for large (small) values of $E_{a}$, the thermal stress aspect of the damp-heat test is less (more) severe than the long-term aging test conditions to determine RTI/RTE.

2. - The addition of humidity during the damp-heat test may affect the numbers in Table 4.

3. - To fully understand the relationship between the RTI/RTE and damp-heat tests, the $E_{a}$ values must be quantified. Furthermore, the combined effects of temperature, moisture, UV, and time need to be considered.

4. - This study should be extended to roof-mounted systems.

Regarding short-term exposure to very high temperatures, we conclude that rack-mounted modules experience temperatures as high as $75^{\circ} \mathrm{C}$ and roof-mounted modules experience temperatures as high as $96^{\circ} \mathrm{C}$. Modules may experience even higher temperatures at the junction box, or if cells are shaded. Some new encapsulant materials may not be able to withstand these high temperatures. It may be valuable to add a test that exposes the module to a high temperature for a short time $(\sim 1 \mathrm{~h})$ to determine whether a radical phase change of a material may have a detrimental effect on the module.

\section{ACKNOWLEDGEMENTS}

We thank J. Thies and G. Fechtmann for useful conversations about RTI and C. Osterwald and B. Sekulic for the data for the ASE system. This work was supported by the U.S. Department of Energy under Contract No. DOE-AC36-08GO28308 with the National Renewable Energy Laboratory.

\section{REFERENCES}

[1] C.R. Osterwald, and T.J. McMahon "History of Accelerated and Qualification Testing of Terrestrial Photovoltaic Modules: A Literature Review," Prog. in PV 17, 2009, pp. 11-33.

[2] J.H. Wohlgemuth, et al. "Using Accelerated Tests and Field Data to Predict Module Reliability and Lifetime," Proc. 23 ${ }^{\text {rd }}$ European PVSEC, Valencia, Spain, 2008, \# 4EP1.2, pp. 2663-2669.

[3] J.H. Wohlgemuth, et al. "Long Term Reliabilty of Photovoltaic Modules," $4^{\text {th }}$ WCPEC 2006, p. 2050.

[4] J.H. Wohlgemuth, D.W. Cunningham, A.M. Nguyen, and J. Miller "Long Term Reliability of PV Modules," Proc. $20^{\text {th }}$ European PVSEC, Barcelona, Spain, 2005, p. 1942.

[5] A. Desombre "Methodology for a Reliability Study of Photovoltaic Modules," Proc. $3^{\text {rd }}$ ECPVSEC, 1980, pp. 741-745.

[6] T. McMahon "Accelerated Testing and Failure of Thinfilm PV Modules," Prog. in PV 12, 2004, pp. 235-248.

[7] J.E. Pickett, D.A. Gibson, S.T. Rice, and M.M. Gardner "Effects of Temperature on the Weathering of Engineering Thermoplastics," Poly. Deg. Stab. 93, 2008, pp. 684-691.

[8] ANSI/UL, "UL 746B Standard for Polymeric materials Long Term Property Evaluations," 2001; IEC 60216-5 "Electrical insulating materials - Thermal endurance properties - Part 5: Determination of relative thermal endurance index (RTE) of an insulating material."

[9] R. Dixon "Thermal Aging Predictions from an Arrhenius Plot with only One Data Point", IEEE Transactions on Electrical Insulation El-15, (4), 1980, pp. 331-334.

[10] UL746C, "Polymeric Materials - Use in Electrical Equipment Evaluations."

[11] http://apps1.eere.energy.gov/buildings/energyplus/, as described in: S. Wilcox and W. Marion, "Users Manual for TMY3 Data Sets" Technical Report NREL/TP-58143156, revised May, 2008.

[12] D.L. King, W.E. Boyson, and J.A. Kratochvil, "Photovoltaic Array Performance Model," Sandia National Laboratories, SAND2004-3535, (2004).

[13] Solar Engineering of Thermal Processes (John Wiley \& Sons, Inc., 1991, $2^{\text {nd }}$ edn. 1991), p. 25.

[14] -http://www.trivia-library.com/a/10-hottest-cities.htm

[15] -http://www.worldclimate.com/

[16] IEC 61215, "Crystalline silicon terrestrial photovoltaic (PV) modules - Design qualification and type approval," IEC 61646, "Thin-film terrestrial photovoltaic (PV) modules - Design qualification and typ approval."

[17] D.H. Otth and R.G. Ross "Assessing Photovoltaic Module Degradation and Lifetime from Long Term Environmental Tests," Proc. $29^{\text {th }}$ Inst. of Environmental Science Annual Meeting, 1983, pp. 121-126. 


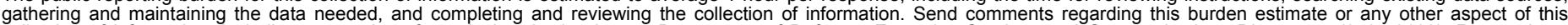

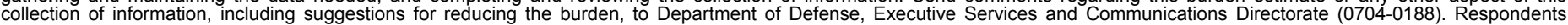

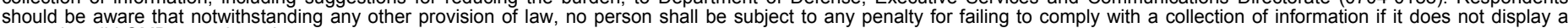

should be aware that notwithstanding

PLEASE DO NOT RETURN YOUR FORM TO THE ABOVE ORGANIZATION.
1. REPORT DATE (DD-MM-YYYY) June 2009
4. TITLE AND SUBTITLE
Evaluation of High-Temperature Exposure of Photovoltaic Modules: Preprint

6. AUTHOR(S)

S. Kurtz, K. Whitfield, D. Miller, J. Wohlgemuth, M. Kempe, N. Dhere, N. Bosco, and T. Zgonena
3. DATES COVERED (From - To)

5a. CONTRACT NUMBER

DE-AC36-08-GO28308

5b. GRANT NUMBER

5c. PROGRAM ELEMENT NUMBER

5d. PROJECT NUMBER

NREL/CP-520-45986

5e. TASK NUMBER

PVB76503

5f. WORK UNIT NUMBER
7. PERFORMING ORGANIZATION NAME(S) AND ADDRESS(ES)

National Renewable Energy Laboratory

1617 Cole Blvd.

Golden, CO 80401-3393

9. SPONSORING/MONITORING AGENCY NAME(S) AND ADDRESS(ES)
8. PERFORMING ORGANIZATION REPORT NUMBER

NREL/CP-520-45986

10. SPONSOR/MONITOR'S ACRONYM(S) NREL

11. SPONSORING/MONITORING AGENCY REPORT NUMBER

12. DISTRIBUTION AVAILABILITY STATEMENT

National Technical Information Service

U.S. Department of Commerce

5285 Port Royal Road

Springfield, VA 22161

\section{SUPPLEMENTARY NOTES}

\section{ABSTRACT (Maximum 200 Words)}

The 2004 version of the IEC 61730 specification requires all polymeric materials used in a photovoltaic module to have a Relative Thermal Index (RTI) at least $20^{\circ} \mathrm{C}$ greater than the module operating temperature measured at $40^{\circ} \mathrm{C}$ ambient. The RTI reflects changes in key properties (e.g., dielectric strength) after long-term exposure at elevated temperature. The RTI determination elucidates the thermal aging more thoroughly than a single-temperature accelerated test, but requires substantial time and may not measure the characteristics that are most relevant to the safe use of a module. There is currently an international debate regarding whether the RTI requirement should be retained or whether other tests would suffice without introducing a new safety risk. This paper explores the thermal exposure of photovoltaic modules in the field so as to provide a technical basis for this debate. Given our current knowledge, for rack-mounted modules, the damp-heat test is a reasonable substitute for the RTI measurement for the majority of materials. Improved knowledge about aging processes is necessary to provide the technical basis for an improved test.

\section{SUBJECT TERMS}

PV; modules; relative thermal index; high-temperature exposure; ultraviolet light;

\begin{tabular}{|c|c|c|}
\hline 16. SECURIT & CLASSIFICAT & N OF: \\
\hline $\begin{array}{l}\text { a. REPORT } \\
\text { Unclassified }\end{array}$ & $\begin{array}{l}\text { b. ABSTRACT } \\
\text { Unclassified }\end{array}$ & $\begin{array}{l}\text { c. THIS PAGE } \\
\text { Unclassified }\end{array}$ \\
\hline
\end{tabular}

\begin{tabular}{|c|c|}
\hline $\begin{array}{l}\text { 17. LIMITATION } \\
\text { OF ABSTRACT }\end{array}$ & $\begin{array}{l}\text { 18. } \\
\text { OFUMBER PAGES }\end{array}$ \\
\hline UL & \\
\hline
\end{tabular}

19a. NAME OF RESPONSIBLE PERSON

19b. TELEPHONE NUMBER (Include area code) 